\title{
Macrocyclic MR contrast agents: evaluation of multiple-organ gadolinium retention in healthy rats
}

Simona Bussi ${ }^{1 *} \mathbb{D}$, Alessandra Coppo ${ }^{1}$, Roberto Celeste ${ }^{1}$, Antonello Fanizzi ${ }^{1}$, Alberto Fringuello Mingo', Andrea Ferraris ${ }^{2}$, Catherine Botteron ${ }^{3}$, Miles A. Kirchin ${ }^{4}$, Fabio Tedoldi ${ }^{1}$ and Federico Maisano ${ }^{2}$

\begin{abstract}
Objectives: The purpose of this study was to compare Gd levels in rat tissues after cumulative exposure to four commercially available macrocyclic gadolinium-based contrast agents (GBCAs).

Methods: Sixty-five male Sprague-Dawley rats were randomized to four exposure groups ( $n=15$ per group) and one control group $(n=5)$. Animals in each exposure group received 20 GBCA administrations (four per week of ProHance ${ }^{\oplus}$, Dotarem $^{\oplus}$, Clariscan ${ }^{\mathrm{TM}}$, or Gadovist ${ }^{\oplus}$ for 5 consecutive weeks) at a dose of $0.6 \mathrm{mmol} / \mathrm{kg}$ bodyweight. After 28-days' recovery, animals were sacrificed and tissues harvested for Gd determination by inductively coupled plasma-mass spectroscopy (ICP-MS). Histologic assessment of the kidney tissue was performed for all animals.

Results: Significantly ( $p \leq 0.005$; all evaluations) lower Gd levels were noted with ProHance ${ }^{\circledast}$ than with Dotarem ${ }^{\oplus}$, Clariscan $^{\text {TM }}$, or Gadovist ${ }^{\oplus}$ in all soft tissue organs: $0.144 \pm 0.015 \mathrm{nmol} / \mathrm{g}$ vs. $0.342 \pm 0.045,0.377 \pm 0.042$, and $0.292 \pm 0.047 \mathrm{nmol} / \mathrm{g}$, respectively, for cerebrum; $0.151 \pm 0.039 \mathrm{nmol} / \mathrm{g}$ vs. $0.315 \pm 0.04,0.345 \pm 0.053$, and $0.316 \pm 0.040 \mathrm{nmol} / \mathrm{g}$, respectively, for cerebellum; $0.361 \pm 0.106 \mathrm{nmol} / \mathrm{g}$ vs. $0.685 \pm 0.330,0.823 \pm 0.495$, and $1.224 \pm 0.664 \mathrm{nmol} / \mathrm{g}$, respectively, for liver; $38.6 \pm 25.0 \mathrm{nmol} / \mathrm{g}$ vs. $172 \pm 134,212 \pm 121$, and $294 \pm 127 \mathrm{nmol} / \mathrm{g}$, respectively, for kidney; and $0.400 \pm 0.112 \mathrm{nmol} / \mathrm{g}$ vs. $0.660 \pm 0.202,0.688 \pm 0.215$, and $0.999 \pm 0.442 \mathrm{nmol} / \mathrm{g}$, respectively, for skin. No GBCA-induced macroscopic or microscopic findings were noted in the kidneys.
\end{abstract}

Conclusions: Less $\mathrm{Gd}$ is retained in the brain and body tissues of rats 28 days after the last exposure to ProHance ${ }^{\circledast}$ compared to other macrocyclic GBCAs, likely due to unique physico-chemical features that facilitate more rapid and efficient clearance.

Keywords: Contrast media, Magnetic resonance imaging, Gadolinium, Pharmacokinetics, Histology, Rats

\section{Key points}

- Macrocyclic gadolinium-based contrast agents (GBCAs) differ in their propensity for Gd retention in rat tissues and organs

- The level of retained Gd may reflect the ease and rapidity of $\mathrm{Gd}$ clearance from tissues and organs after administration

\footnotetext{
* Correspondence: simona.bussi@bracco.com

${ }^{1}$ Bracco Imaging SpA, Bracco Research Centre, Via Ribes 5, 10010 Colleretto Giacosa, TO, Italy

Full list of author information is available at the end of the article
}

- Macrocyclic GBCAs have no impact on rat kidney tissue histology, up to the tested cumulative dose of $12 \mathrm{mmol} / \mathrm{kg}$

\section{Introduction}

It is well established that trace amounts of gadolinium (Gd) are retained in brain and body tissues following the administration of both linear and macrocyclic gadolinium-based contrast agents (GBCAs) [1, 2]. Although the nature of the retained Gd has still to be elucidated, there is strong evidence that GBCAs enter into brain tissues predominantly in the cerebrospinal fluid (CSF) and that Gd retention occurs following its passage from the perivascular space to the interstitial space as 
part of the normal glymphatic system [3-7]. This mechanism may explain why $\mathrm{Gd}$ is retained in the human brain even in the absence of intracranial abnormalities potentially affecting blood-brain barrier permeability [8].

Whereas early reports focused primarily on differences between linear and macrocyclic GBCAs $[9,10]$, it is now apparent that there are differences also amongst GBCAs of the same class [11-13]. In a recent comparison of three macrocyclic GBCAs in rodents, Bussi et al. [12] ascribed lower levels of $\mathrm{Gd}$ retention in the brain after gadoteridol (ProHance; Bracco Imaging) to differences in the physico-chemical properties of the GBCAs, postulating that the low molecular weight of gadoteridol, combined with lower viscosity and slightly higher lipophilicity [14] compared to gadobutrol (Gadovist ${ }^{\circ}$; Bayer Healthcare) [15] and gadoterate (Dotarem; ; Guerbet) [16] may facilitate its more efficient clearance via the glymphatic system.

Recently, a fourth macrocyclic GBCA (Clariscan ${ }^{\text {th }}$, gadoteric acid; GE Healthcare) has become available in some countries. This GBCA has the same formulation as Dotarem $^{\circ}$ [17] but has never been included in either clinical or non-clinical studies of Gd retention. The aim of our study was to confirm and extend the findings of Bussi et al. [12] by assessing the extent to which Gd is retained in rat brain and body tissues after serial administration not only of Dotarem ${ }^{\circ}$, Gadovist ${ }^{\circ}$, and ProHance ${ }^{\circ}$ but also of the newer GBCA Clariscan ${ }^{\text {Tw4 }}$. At variance with the study of Bussi et al. [12], we adopted validated analytical methods with lower limits of quantification for liver and skin samples to determine whether significant differences in Gd retention are also seen in these tissues. Additional novel aims were to evaluate microscopically the possible impact of these GBCAs on kidney tissue histology and to assess whether there is any influence of GBCA osmolarity (specifically Gadovist $0.5 \mathrm{M}$ vs. Gadovist $1.0 \mathrm{M}$ ) on the levels of $\mathrm{Gd}$ retention. Finally, we performed computational studies to determine whether hydration-related parameters of the three macrocyclic molecules correlate with $\mathrm{Gd}$ clearance from tissues.

\section{Materials and methods}

We followed the methods of Bussi et al. [12]. The study was performed at Charles River Lyon, France (AAALAC accredited), according to site-specific procedures established by the relevant Quality Assurance Unit. Procedures were conducted according to national and international regulations (L.D. 26/2014; Directive 2010/63/EU), Decree 2013-118 relating to the protection of animals used in scientific experiments described in the Journal Officiel de la République Française on 01 February 2013.

\section{Animal study}

Sixty-five male Sprague-Dawley OFA (SD) rats (Charles River Laboratories, France) aged 6 weeks and weighing
$129.0-232.5 \mathrm{~g}$ at the start of treatment were utilized. After 8 days of acclimation, the animals were randomized to one of five groups: group A (saline; $n=5$ ), group B (ProHance $; n=15)$, group C (Dotarem $\left.{ }^{\circ} ; n=15\right)$, group $\mathrm{D}\left(\right.$ Clariscan $\left.^{\mathrm{nx}} ; n=15\right)$, and group $\mathrm{E}$ (Gadovist $\left.{ }^{\circ} ; n=15\right)$. Gadovist $^{\circ}$ was diluted 1:1 with water for injection (WFI) prior to injection to achieve a similar concentration $(0.5$ $\mathrm{M})$ and administered volume to those of the other GBCAs investigated. Animals were housed under controlled conditions at $22 \pm 3{ }^{\circ} \mathrm{C},>35 \%$ relative humidity and $12 \mathrm{~h}$ dark/light cycles. Food pellets (A04C-10; Safe, France) and filtered water from municipal services were provided ad libitum.

Animals in groups B, C, D, and E were administered the following contrast agents, respectively: ProHance ${ }^{\circ}$, batch n. V17628, expiry: 06/2020; Dotarem ${ }^{\circ}$, batch $n$. 17GD009B01, expiry: 01/2020; Clariscan ${ }^{\mathrm{TN}}$, batch $\mathrm{n}$. 13794731, expiry: 12/2018; Gadovist ${ }^{\circ}$ batches n. 44617D and $72649 \mathrm{~A}$, expiry: $11 / 2017$ and $05 / 2020$, respectively. Administration of GBCA or saline was performed at room temperature at the same time each day (between $8.00 \mathrm{a} . \mathrm{m}$. and $12.00 \mathrm{a} . \mathrm{m}$.) into the lateral vein of the tail at an injection rate of $2 \mathrm{~mL} / \mathrm{min}$ using a Harvard infusion pump. All animals received saline solution $(0.9 \% \mathrm{w} /$ $\mathrm{v} \mathrm{NaCl}$ ) or the respective GBCA at $1.2 \mathrm{~mL} / \mathrm{kg}$ bodyweight four times a week for 5 consecutive weeks, for a total cumulative dose of $12 \mathrm{mmol} / \mathrm{kg}$ bodyweight. The daily administered dose $(0.6 \mathrm{mmol} / \mathrm{kg}$ bodyweight $)$ corresponds to a clinical dose of $0.1 \mathrm{mmol} / \mathrm{kg}$ bodyweight, based on the extrapolation factor for rats [18]. After the 5 -week treatment period, each animal was allowed a recovery period of 28 days (corresponding to approximately 2.5 human years $[19,20])$ before sacrifice.

\section{Observations}

During the treatment period, all animals were inspected before and after dosing for any clinical signs or reactions to treatment. During the treatment-free period, all animals were inspected once daily. A full clinical examination was performed pre-test and then weekly during the treatment and treatment-free periods.

\section{Pathology}

At the end of the treatment-free period, all animals were necropsied. The animals were killed by carbon dioxide inhalation and exsanguination. After exsanguination and blood sampling, a complete macroscopic post-mortem examination was performed; abnormal findings, if any, were recorded. Thereafter, each animal was dissected to obtain tissues (cerebrum, cerebellum, liver, right kidney, right femur, and skin) for inductively coupled plasmamass spectrometry (ICP-MS) determination of gadolinium. A total of 455 tissue/blood samples were collected (65 animals; 6 tissue samples, and 1 blood sample per 
animal). At the same time, the left kidney was dissected and processed to slides for histopathologic evaluation by an experienced ECVP-qualified pathologist (Charles River Laboratories, France).

\section{Determination of total gadolinium}

All procedures were carried out at Bracco Research Centre (Colleretto Giacosa, Turin, Italy). Blood samples $(0.5 \mathrm{~mL})$ were mixed $1: 2$ with nitric acid $(65 \% \mathrm{w} / \mathrm{w}$, Extrapure, Merck). Cerebrum and cerebellum samples were weighed and freeze-dried, and then suspended in 1 $\mathrm{mL}$ of nitric acid. The liver, kidney, and skin samples were weighed, freeze-dried, and ground in a mortar. Approximately $0.2 \mathrm{~g}$ of each organ was then weighed and suspended in $1 \mathrm{~mL}$ of nitric acid. Femurs were weighed and dissolved in $1 \mathrm{~mL}$ of nitric acid. All nitric acid solutions were stored at $4{ }^{\circ} \mathrm{C}$ for at least $12 \mathrm{~h}$ before digestion. Sample mineralization was performed by subjecting the samples to a wet ashing process $\left(95 \mathrm{~min}\right.$ at $180^{\circ} \mathrm{C}$ for blood, $110 \mathrm{~min}$ at $180^{\circ} \mathrm{C}$ for the other organs) in a microwave oven system (MARS-5; CEM Corporation). The mineralized samples were quantitatively transferred to disposable Falcon tubes, diluted to $20 \mathrm{~mL}$ with $2 \%$ nitric acid, filtered at $0.45 \mu \mathrm{m}$, and then analyzed by ICP-MS using validated analytical methods. Internal standardization was performed using ${ }^{153} \mathrm{Eu}$. The calibration blanks, calibration standards, and control standard solutions for each analytical sequence were prepared in $2 \%$ nitric acid by dilution of a gadolinium oxide $\left(\mathrm{Gd}_{2} \mathrm{O}_{3}\right)$ standard solution $\left(1000 \mu \mathrm{g} / \mathrm{mL}\right.$ in $2 \% \mathrm{HNO}_{3}$, Certipur, Merck).

The lower limit of quantitation (LOQ) for gadolinium was $0.1 \mathrm{nmol} / \mathrm{mL}$ for blood, $0.1 \mathrm{nmol} / \mathrm{g}$ for cerebrum/ cerebellum, $0.6 \mathrm{nmol} / \mathrm{g}$ for femur, and $1.5 \mathrm{nmol} / \mathrm{g}$ for kidney. The LOQ for each of these tissues was verified for accuracy and precision by spiking in triplicate explanted blank organs from untreated animals (not included in this study) with the corresponding amounts of gadolinium and determining the respective percent recoveries. For liver and skin, the LOQ was determined to be $0.1 \mathrm{nmol} / \mathrm{g}$. For these two tissues, the reported values were extrapolated concentrations for samples in which the signal-to-noise $(\mathrm{S} / \mathrm{N})$ ratio was at least 10 , with the noise corresponding to the mean tissue signal in salinetreated control animals. These extrapolated values were considered conservative, since both the European Medicines Agency (EMA) [21] and Food and Drug Administration (FDA) [22] recommend that the analyte response at the LOQ is at least five times the zero calibrator.

\section{Assessment of kidney tissue histology}

The left kidney of all animals was dissected and fixed in $10 \%$ neutral formalin for slide preparation. All slides were stained with hematoxylin and eosin. If abnormal findings were observed, these were graded using a fivepoint scale from 1 (minimal/very few/very small) to 5 (massive/very many/very large).

\section{Computational studies}

Computational studies were performed to determine whether the minor structural differences between the macrocyclic GBCA molecules impact hydration-related parameters (hydrophilic surface and solvation enthalpy), which reflect the tendency to form ionic or hydrogen bonds primarily with water, but possibly also with hydrophilic macromolecules of the extracellular matrix in body tissues. The hydrophilic surface is a partition of the space around the molecule that defines regions open to interaction with water molecules; the higher the hydrophilic surface value, the higher the number of interactions. The interactions with water molecules can be of different nature (ion-dipole, hydrogen bonding, van der Waals forces), meaning that different energy (enthalpy) levels are released when the molecule is put in water (hydrated). Calculation of hydrophilic surface and solvation enthalpy for gadoterate, gadobutrol and gadoteridol was based, as starting geometries, on the crystallographic structures of the molecules [23-25]. All ab initio calculations were performed at the restricted Hartree-Fock level with the Gaussian $09 \mathrm{~W}$ program [26] using the (1 s-4d, 4f7) effective core pseudopotentials with the 5s4p3d-Gaussian-type orbitals valence basis set for the $\mathrm{Gd}$ atom [27]. Full geometry optimization of the starting structures was carried out with the 3-21G basis set for the atoms of the ligands, considering one inner-sphere water molecule $(q=1)$.

On the optimized structures, solvation energy was determined by means of single point energy calculations performed with the 6-31G** basis set for the other atoms of the ligands, both in vacuo and in solution, by adopting the polarizable continuum model as implicit solvation model [28]. Hydrophilic surface area values were calculated at the Molecular Mechanics level on the ab initio optimized structures, by means of Goodford's GRID algorithm [29], as implemented in the Maestro software package [30].

\section{Statistical analysis}

Gadolinium concentration was expressed as nanomoles per gram wet tissue in the case of cerebrum, cerebellum, liver, femur, kidneys, and skin and as nanomoles per milliliter in the case of blood. The Dixon test [31, 32] was used before formal data analysis to highlight possible anomalous data points. Levene's test [33] was used to test the equality of variance across groups and Shapiro-Wilk's test [34] was used to assess the normality of the data distribution in each group. Data with 
homogeneous variances and normal distribution in all groups were analyzed using ANOVA followed by Dunnett's test [35]. Data showing non-homogeneous variances or a non-normal distribution in at least one group were analyzed using the Kruskal-Wallis test followed by Wilcoxon's rank-sum test [35]. All statistical analyses were performed at Charles River Laboratories, using SAS software, version 8.2 (Cary, USA).

\section{Results}

All animals successfully underwent all aspects of the study. No unexpected changes in bodyweight were noted and no adverse signs or symptoms were observed for any animal. No gross pathological tissue changes were noted at sacrifice.

The mean $( \pm \mathrm{SD})$ Gd contents across groups and tissue types are presented in Fig. 1 and Table 1. After the 28-day recovery period, the mean Gd levels in the blood of all groups and in all organs from the control group were below the LOQ. Conversely, measurable amounts of $\mathrm{Gd}$ were detected in all the tested organs, but with marked differences across the GBCA groups.

The highest mean Gd levels in the cerebrum and cerebellum were noted after Clariscan followed by Dotarem and Gadovist and finally ProHance. The Gd levels after ProHance were significantly ( $p \leq 0.005$; all evaluations) lower than the levels noted with Dotarem, Clariscan, and Gadovist in both the cerebrum $(0.144 \pm 0.0147 \mathrm{nmol} / \mathrm{g}$ vs. $0.342 \pm 0.0448 \mathrm{nmol} / \mathrm{g}, 0.377 \pm 0.0421 \mathrm{nmol} / \mathrm{g}$, and $0.292 \pm$ $0.0473 \mathrm{nmol} / \mathrm{g}$, respectively) and cerebellum $(0.151 \pm$ $0.0393 \mathrm{nmol} / \mathrm{g}$ vs. $0.315 \pm 0.0400 \mathrm{nmol} / \mathrm{g}, 0.345 \pm 0.0525$ $\mathrm{nmol} / \mathrm{g}$, and $0.316 \pm 0.0397 \mathrm{nmol} / \mathrm{g}$, respectively). The $\mathrm{Gd}$ level after Gadovist in the cerebrum was higher than after ProHance but significantly lower than after Dotarem $(p \leq$ $0.01)$ and Clariscan $(p \leq 0.005)$. The difference between Dotarem and Clariscan was not significant $(p>0.05)$ in the cerebellum but was just beyond the limit of significance in the cerebrum $(0.342 \pm 0.045 \mathrm{nmol} / \mathrm{g}$ and $0.377 \pm$ $0.042 \mathrm{nmol} / \mathrm{g}$, respectively; $p=0.044$ ).

Similar findings were noted in the right kidney and liver. Significantly lower ( $p \leq 0.005$; all evaluations) Gd levels were noted after ProHance than after Dotarem, Clariscan, and Gadovist in both tissues $(38.6 \pm 25.0$ $\mathrm{nmol} / \mathrm{g}$ vs. $172 \pm 134 \mathrm{nmol} / \mathrm{g}, \quad 212 \pm 121 \mathrm{nmol} / \mathrm{g}$, and $294 \pm 127 \mathrm{nmol} / \mathrm{g}$ in the right kidney, respectively, and $0.361 \pm 0.106 \mathrm{nmol} / \mathrm{g}$ vs. $0.685 \pm 0.330 \mathrm{nmol} / \mathrm{g}, \quad 0.823 \pm$ $0.495 \mathrm{nmol} / \mathrm{g}$, and $1.22 \pm 0.664 \mathrm{nmol} / \mathrm{g}$ in the liver, respectively). Unlike in the cerebrum, the mean Gd level for Gadovist was significantly higher $(p \leq 0.05)$ than that for Dotarem in the right kidney and both Dotarem ( $p \leq$ $0.01)$ and Clariscan $(p \leq 0.05)$ in the liver.

Analogous results were found in the skin. The Gd level after ProHance $(0.400 \pm 0.112 \mathrm{nmol} / \mathrm{g})$ was significantly lower ( $p \leq 0.005$; all evaluations) than after Dotarem
$(0.660 \pm 0.202 \mathrm{nmol} / \mathrm{g})$, Clariscan $(0.688 \pm 0.215 \mathrm{nmol} / \mathrm{g})$, and Gadovist $(0.999 \pm 0.442 \mathrm{nmol} / \mathrm{g})$. The value for Gadovist was significantly higher than that for both Dotarem $(p \leq 0.01)$ and Clariscan $(p \leq 0.05)$.

In the femur, significantly higher $(p \leq 0.005$, all evaluations) $\mathrm{Gd}$ levels were noted with Gadovist than with ProHance, Dotarem, and Clariscan $(16.1 \pm 4.51 \mathrm{nmol} / \mathrm{g}$ vs. $8.48 \pm 1.87 \mathrm{nmol} / \mathrm{g}, \quad 6.28 \pm 3.08 \mathrm{nmol} / \mathrm{g}$, and $9.44 \pm$ $4.01 \mathrm{nmol} / \mathrm{g}$, respectively). No significant differences were noted between ProHance, Dotarem, and Clariscan.

\section{Assessment of kidney tissue histology}

There were no microscopic observations and no abnormal findings in the left kidney that were considered to be associated with any of the GBCAs (Fig. 2). Any observations were considered incidental and within the range of expected spontaneous changes in rats.

\section{Computational studies}

We calculated the hydrophilic surface and hydration enthalpy for the gadoterate, gadobutrol, and gadoteridol molecules, as indicators of the number and strength of hydrogen bonds and ionic interactions established during dissolution (Table 2). The lowest absolute values in both cases were obtained for gadoteridol.

\section{Discussion}

No clinical signs, symptoms, or adverse clinical outcomes have yet been associated with retained Gd in the brain following the repeated administration of any GBCA [36, 37]. Nevertheless, because macrocyclic GBCAs as a class have been associated with lower levels of $\mathrm{Gd}$ retention in animal studies [9-11, 13], and with only minor/negligible increases in T1-signal in the dentate nucleus or globus pallidus on unenhanced T1weighted brain images [38-40] when compared with certain linear GBCAs, the perception is that macrocyclic GBCAs are in some way "safer." Consequences of this perception have been the suspension by the EMA in Europe of all general-purpose linear agents, and the widespread assumption that all GBCAs within each class are essentially similar and interchangeable. That this is not the case has been highlighted by several recent studies that have shown significant differences amongst GBCAs of the same class in terms of the levels of Gd retained [11-13].

\section{Tissue Gd concentrations}

Our results confirm and extend those of Bussi et al. [12] in showing significantly lower (between 2 and 2.6 times lower) levels of $\mathrm{Gd}$ in rat brain (cerebrum and cerebellum) after cumulative administration of ProHance than after equivalent cumulative administration of Dotarem, Clariscan, or Gadovist. These findings have additionally 


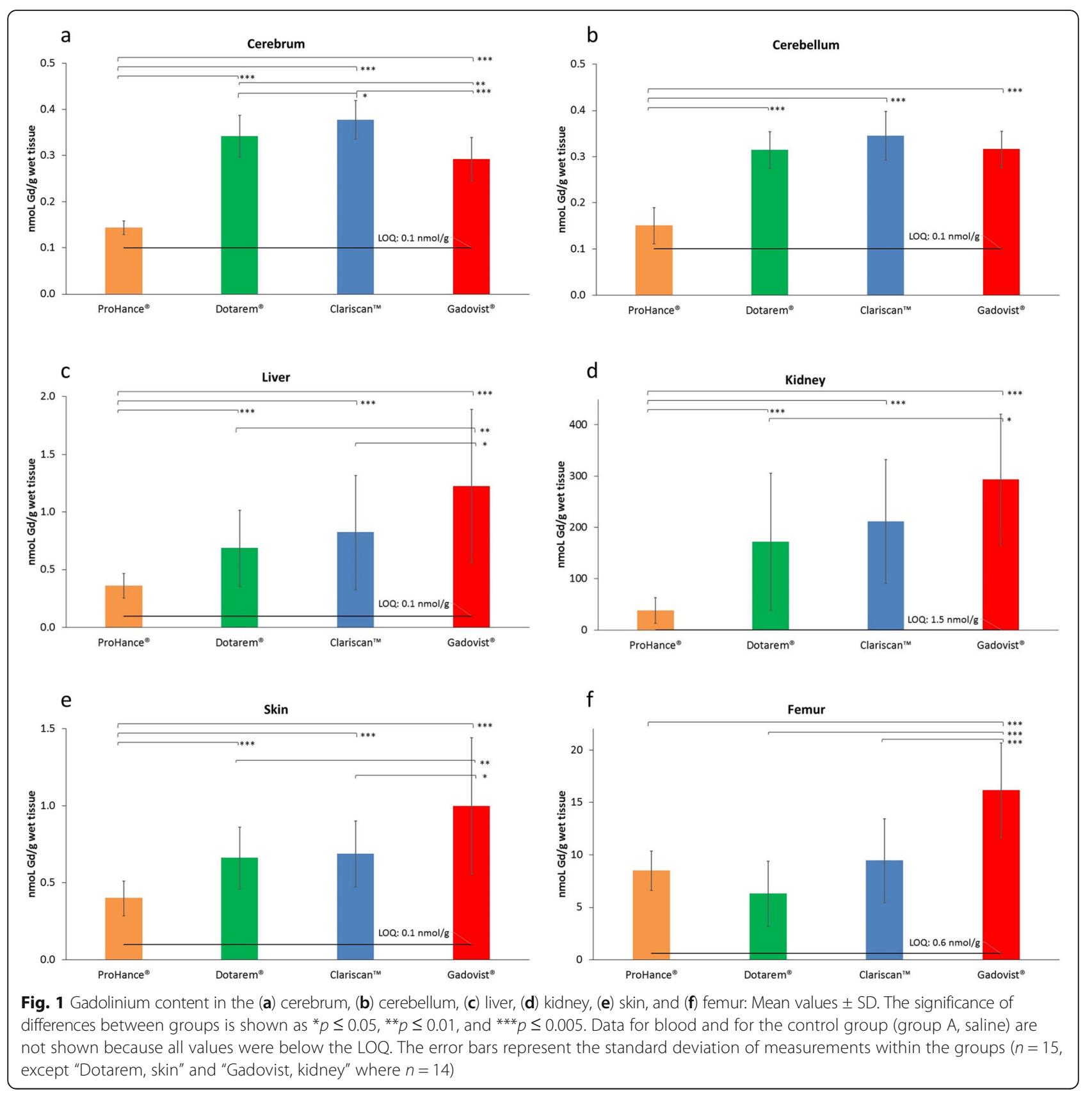

been confirmed by Jost et al. [13] who reported roughly threefold lower levels of Gd in rat cerebellum after ProHance than after Dotarem or Gadovist $(0.19 \mathrm{nmol} / \mathrm{g}$ vs. $0.54 \mathrm{nmol} / \mathrm{g}$ and $0.63 \mathrm{nmol} / \mathrm{g}$, respectively) at 5 weeks, after 8 administrations of each GBCA at $1.8 \mathrm{mmol} / \mathrm{kg}$ per injection. Although the retained Gd levels were similar for the three macrocyclic GBCAs at 26 and 52 weeks after the last administration [13], these findings suggest that ProHance is cleared more rapidly than Dotarem or Gadovist, possibly reflecting more efficient migration of the gadoteridol molecule towards the venous and lymphatic vessels in the interstitial space. In this regard, it appears molecular migration is promoted not only by convection, which is unaffected by small differences in otherwise similar molecules, but also by diffusion, which is highly dependent on the intrinsic molecular properties of the GBCAs and their capacity for interaction with the complex surrounding matrix [41].

\section{Gd clearance from soft tissues}

As noted in Bussi et al. [12], of the three macrocyclic molecules investigated, gadoteridol has a low molecular 
Table 1 Gadolinium content in the blood, cerebrum, cerebellum, liver, kidney, skin, and femur (mean values \pm SD)

\begin{tabular}{|c|c|c|c|c|c|c|c|}
\hline Group (ID) & $\begin{array}{l}\text { Blood } \\
\text { (nmol/mL) }\end{array}$ & $\begin{array}{l}\text { Cerebrum } \\
(\mathrm{nmol} / \mathrm{g})\end{array}$ & $\begin{array}{l}\text { Cerebellum } \\
(\mathrm{nmol} / \mathrm{g})\end{array}$ & Liver (nmol/g) & $\begin{array}{l}\text { Kidney (right) } \\
\text { (nmol/g) }\end{array}$ & Skin $(\mathrm{nmol} / \mathrm{g})$ & Femur (nmol/g) \\
\hline Control (A) & $<\mathrm{LOQ}$ & $<\mathrm{LOQ}$ & $<\mathrm{LOQ}$ & $<\mathrm{LOQ}$ & $<\mathrm{LOQ}$ & $<\mathrm{LOQ}$ & $<\mathrm{LOQ}$ \\
\hline ProHance (B) & $<\mathrm{LOQ}^{\mathrm{a}}$ & $0.144 \pm 0.015^{b}$ & $0.151 \pm 0.039$ & $0.361 \pm 0.106$ & $38.6 \pm 25.0$ & $0.400 \pm 0.112$ & $8.48 \pm 1.87$ \\
\hline Dotarem (C) & $<\mathrm{LOQ}$ & $0.342 \pm 0.045^{\circ 00}$ & $0.315 \pm 0.040^{\circ 00}$ & $0.685 \pm 0.330^{\circ 00}$ & $172 \pm 134^{000}$ & $0.660 \pm 0.202^{\circ 00}$ & $6.28 \pm 3.08$ \\
\hline Clariscan (D) & $<\mathrm{LOQ}$ & $0.377 \pm 0.042^{\circ 0, *}$ & $0.345 \pm 0.053^{000}$ & $0.823 \pm 0.495^{\circ 00}$ & $212 \pm 121^{000}$ & $0.688 \pm 0.215^{\circ 00}$ & $9.44 \pm 4.01$ \\
\hline Gadovist (E) & $<L O Q$ & 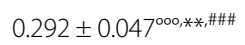 & $0.316 \pm 0.040^{\circ 00}$ & $1.22 \pm 0.664^{000, * *, \#}$ & $294 \pm 127^{000 * *}$ & $0.999 \pm 0.442^{\circ 00, * *, \#}$ & $16.1 \pm 4.51^{\circ 00, * *}$ \\
\hline
\end{tabular}

$n=5$ for control animals; $n=15$ for all other groups except "Dotarem, skin" and "Gadovist, right kidney" where $n=14$

Significance vs. group B (ProHance): ${ }^{\circ 0} p \leq 0.01,{ }^{\circ 00} p \leq 0.005$; vs. group C (Dotarem): ${ }^{*} p \leq 0.05,{ }^{* *} p \leq 0.01,{ }^{* * *} p \leq 0.005 ;$ vs. group D (Clariscan): ${ }^{\#} p \leq 0.05,{ }^{\# \# \#} p \leq 0.005$

${ }^{\mathrm{a}} 1$ out of 15 values $>$ LOQ $(0.165)$

${ }^{b} 7$ out of 15 values $<$ LOQ

weight and other properties that would favor fewer interactions with the surrounding matrix and thus more rapid diffusion and clearance than is the case with gadobutrol and gadoterate. Specifically, since all three molecules are hydrophilic, any interactions with the surrounding matrix that would hinder diffusion leading to slower clearance are likely to occur through hydrogen bonding (e.g., with collagen) and ionic interactions (e.g., with proteoglycan-associated cations). With regards to hydrogen bonding, the gadoteridol molecule carries only one hydroxy group, while the gadobutrol molecule carries three (Fig. 3). As a result, fewer hydrogen bonds are to be expected with gadoteridol than with gadobutrol, resulting in fewer interactions with the surrounding matrix. Likewise, the gadoteridol molecule is non-ionic and thus would be expected to have fewer electrostatic interactions with components of the extracellular matrix than the ionic gadoterate molecule which carries a net negative charge [42]. Our findings for the hydrophilic surface and hydration enthalpy of the three molecules lend support to the initial findings of Bussi et al. [12]. Both these parameters are indicators of the number and strength of hydrogen bonds and ionic interactions established during dissolution in water. The lowest absolute values in both cases were obtained for gadoteridol (Table 2), suggesting that the propensity to establish dipole-dipole interactions with macromolecules rich in hydrogen donor/acceptor groups or ionic charges is lower for gadoteridol than for gadobutrol and gadoterate, respectively.

Of notable interest, we also found significantly lower $\mathrm{Gd}$ levels in kidney, liver, and skin after ProHance than after all other GBCAs. Given the strikingly similar profiles of the measured GBCA levels across all soft tissue organs, with ProHance consistently returning lower levels of retained Gd, it is likely the unique physico-chemical properties of the gadoteridol molecule may be relevant not only in the brain $[12,13]$ but also across all soft tissues.

\section{Gd levels in bone}

Our findings for Gd levels in the femur confirm those of Bussi et al. [12] with significantly higher $(p \leq 0.005$, all evaluations) levels for Gadovist and non-significantly lower levels for Dotarem relative to ProHance and Clariscan. As in other tissues, the higher Gd levels with Gadovist in bones may reflect increased hydrogen bonding of the gadobutrol molecule with collagen-rich regions [45]. Notably, Lord et al. [46] recently reported Gd levels in the bones of subjects exposed to Gadovist that

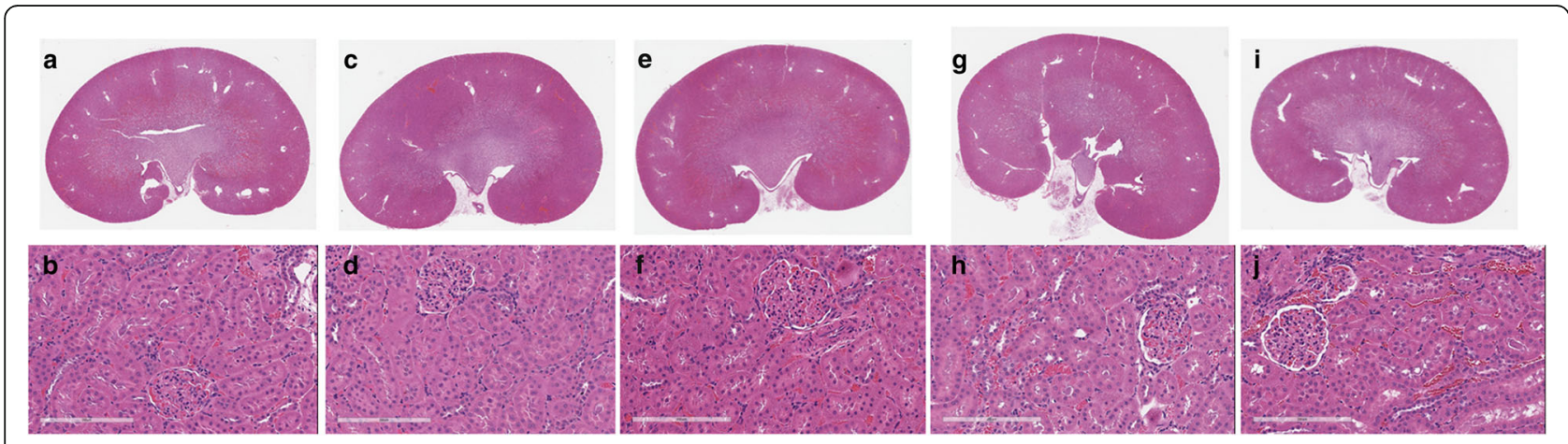

Fig. 2 Representative overviews and high magnifications ( $(\mathrm{bar}=200 \mu \mathrm{m})$ of kidneys from control animals $(\mathbf{a}$ and $\mathbf{b})$ and from animals administered a total cumulative dose of $12 \mathrm{mmol} / \mathrm{kg}$ bodyweight of ProHance (c and $\mathbf{d})$, Dotarem (e and $\mathbf{f})$, Clariscan ( $\mathbf{g}$ and $\mathbf{h}$ ), and Gadovist (i and $\mathbf{j})$. None of the kidneys showed any histologic abnormalities 
Table 2 Physico-chemical features of the gadoterate, gadobutrol, and gadoteridol molecules

\begin{tabular}{|c|c|c|c|}
\hline & $\begin{array}{l}\text { Gadoterate } \\
\text { (Dotarem/Clariscan) }\end{array}$ & $\begin{array}{l}\text { Gadobutrol } \\
\text { (Gadovist) }\end{array}$ & $\begin{array}{l}\text { Gadoteridol } \\
\text { (ProHance) }\end{array}$ \\
\hline$k_{d}\left(s^{-1}\right)^{a}$ & $7.17 \times 10^{-14}$ & $1.11 \times 10^{-12}$ & $1.15 \times 10^{-11}$ \\
\hline$t_{1 / 2}(\text { years })^{b}$ & 306,549 & 19,801 & 1911 \\
\hline $\begin{array}{l}\text { Hydrophilic } \\
\text { Surface }\left(\AA^{2}\right)\end{array}$ & 491 & 404 & 353 \\
\hline $\begin{array}{l}\text { Solvation } \\
\text { enthalpy (kcal/mol) }\end{array}$ & -36 & -12 & -9 \\
\hline
\end{tabular}

${ }^{\mathrm{a}} k_{\mathrm{d}}$ are the rate constants that characterize the dissociation of GBCA complexes in $0.15 \mathrm{M} \mathrm{NaCl}$ at $25^{\circ} \mathrm{C}$ and $\mathrm{pH}=7.4[43,44]$

${ }^{b_{t / 2}}$ is the half-life (years) of the dissociation reactions of GBCA complexes in $0.15 \mathrm{M} \mathrm{NaCl}$ at $25^{\circ} \mathrm{C}$ and $\mathrm{pH}=7.4\left(t_{1 / 2}=\ln 2 / k_{\mathrm{d}}\right)[43,44]$

were not dissimilar to the level reported for a subject exposed to the linear GBCA Omniscan, which is known to lead to greater $\mathrm{Gd}$ retention in bones than ProHance [47-49]. The lack of any relevant differences for gadoterate and gadoteridol may be because the extracellular matrix is mineralized in bones, which prevents water flow or diffusion and excludes the contribution of these phenomena to product clearance.

\section{Histologic evaluation of kidney tissue}

Amongst the tissues evaluated, the highest levels of $\mathrm{Gd}$ were noted in the kidney, presumably reflecting the fact that this organ is directly involved in GBCA elimination. As in liver and skin, the lowest levels were noted for ProHance followed by Dotarem and Clariscan and finally Gadovist. These findings again confirm those of Bussi et al. [12] and are supported by results from McDonald et al. [11] who found markedly higher median Gd levels in rat kidney at 7 days after 20 administrations of 2.5 $\mathrm{mmol} / \mathrm{kg}$ Gadovist $(555 \mu \mathrm{g} \mathrm{Gd} / \mathrm{g}$ of tissue) than after the same dose of ProHance (168 $\mu \mathrm{g} \mathrm{Gd/g}$ of tissue).
At variance with our findings, McDonald et al. [11] found more advanced ultrastructural changes in kidneys of ProHance-exposed animals than in kidneys of animals exposed to Gadovist, MultiHance, and Omniscan. These changes included advanced loss of the normal cytoarchitecture of the proximal convoluted tubule, alterations in glomerular structure and filling of Bowman space with matrix and cellular debris, and loss of the outer mitochondrial membrane [11]. Our study revealed no evidence of any macroscopic or microscopic alterations of renal tissues with any GBCA relative to control animals and no evidence of any specific difference with ProHance relative to the other macrocyclic GBCAs. Rather than reflecting a cytotoxic effect of ProHance, the histologic findings described by McDonald et al. [11] are more suggestive of a rat-specific pathology called chronic progressive nephropathy (CPN) [50, 51], and it is possible that the relatively harsh treatment regimen utilized (a cumulative dose of $50 \mathrm{mmol} / \mathrm{kg}$ ) led to exacerbation of CPN in certain rats. Importantly, CPN has no human counterpart and is not relevant for extrapolation in human risk assessment [52].

\section{Effects of GBCA formulation properties}

Our study differed from that of Bussi et al. [12] in that we included Clariscan for the first time in a Gd retention study and diluted the Gadovist formulation 1:1 with WFI prior to injection. Moreover, thanks to the lower LOQ of the ICP-MS analytical method, we report here also Gd levels in the skin and liver. A comparison of Gd levels across all tissues revealed consistently slightly higher mean levels after Clariscan than after Dotarem although borderline statistical significance $(p=0.044)$ was attained only in the cerebrum. Since the two GBCAs are formulated similarly, the reason for the slight difference

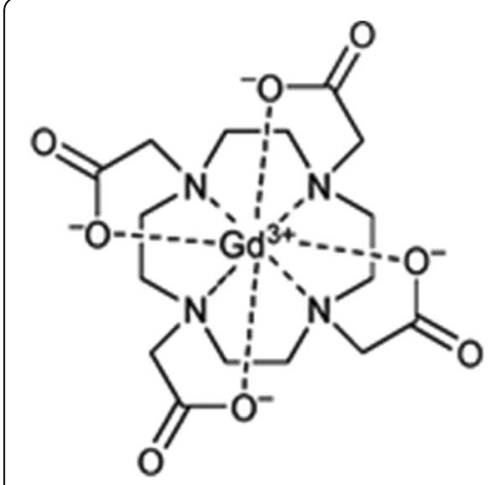

gadoterate ion MW: 558.6 Dotarem/Clariscan

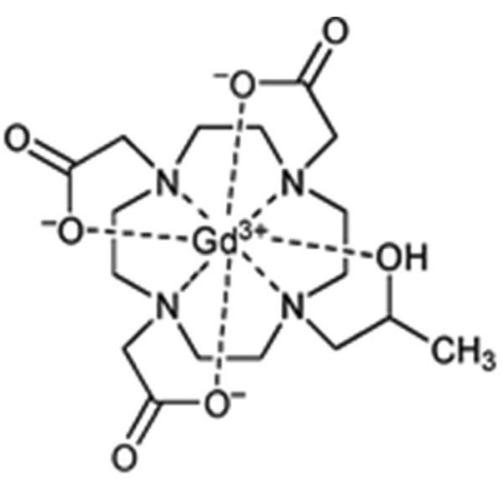

gadoteridol MW: 558.7 ProHance

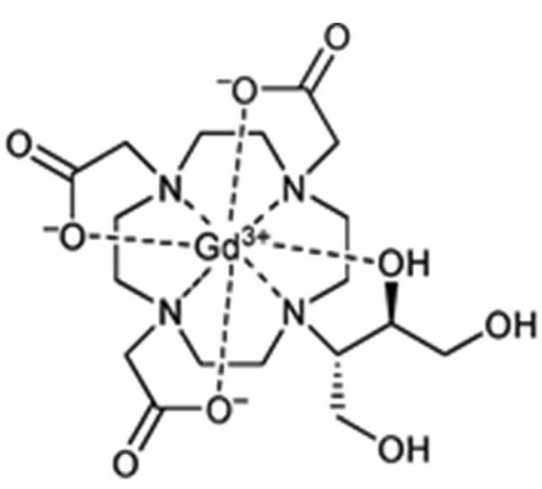

gadobutrol MW: 604.7 Gadovist

Fig. 3 Chemical structures and molecular weights (MW) of macrocyclic GBCAs 
is unclear and should be the subject of further study. Concerning the dilution of Gadovist, this was performed to rule out the possibility that the higher Gd levels in brain tissue observed by Bussi et al. [12] were due to a transient osmotic shock of the blood-brain or blood-CSF barriers caused by the higher concentration of the Gadovist formulation. That the brain Gd levels in our study and in that of Bussi et al. [12] were both approximately twofold higher with Gadovist compared to ProHance suggests that transient osmotic shock is not a reason for the higher Gd levels observed with Gadovist.

\section{Chelate stability}

A final consideration concerns the stabilities of the different macrocyclic agents. In all cases, the dissociation half-life exceeds 1900 years at $25^{\circ} \mathrm{C}$ in $0.15 \mathrm{M} \mathrm{NaCl}$ (Table 2). That none of the agents would dissociate at any point during a patients' lifetime is suggested by Birka et al. [53] who determined trace levels of intact gadoteridol in the skin of a patient on dialysis who had received ProHance 8 years earlier. That ProHance does not dissociate was also suggested by Gianolio et al. [54] who noted that the amount of residual intact gadoteridol in rat brain after repeat administrations of ProHance corresponded to the total amount of retained Gd. These findings imply that differences between macrocyclic agents in terms of thermodynamic and kinetic stability are irrelevant and have no impact on the levels of retained Gd.

\section{Study limitations}

As with all animal studies, our findings are merely suggestive of the human clinical situation rather than definitive. Healthy animals cannot entirely reproduce the complex physiologic situation in humans and such limitations and restrictions should be borne in mind when decisions are made regarding GBCA usage and safety. For example, whereas Jost et al. [3] reported nearcomplete clearance of all GBCAs from rat CSF at $24 \mathrm{~h}$ after a threefold human equivalent dose of $1.8 \mathrm{mmol} / \mathrm{kg}$ bodyweight, Nehra et al. [6] reported significant Gd levels in human CSF at 24 days after a single standard clinical dose of $0.1 \mathrm{mmol} / \mathrm{kg}$ intravenous Gadovist. On the other hand, comparative studies can point to inherent differences between GBCAs, which might translate to the human clinical situation even if the precise human physiologic situation differs. Our results confirm those of others [11-13, 47] in noting lower overall Gd levels in animal tissues after repeated exposure to ProHance than after similar repeated exposure to other GBCAs.

A further possible limitation of our study is that $\mathrm{Gd}$ levels were determined at only one time point, 28 days, after the last GBCA administration. A recent review [55] suggested that measurements be made at both early (days/weeks) and late (1-2 years) time points after the last administration, since $\mathrm{Gd}$ clearance from brain tissue is a relatively slow process. Apart from issues concerning the duration, cost, ethics, and practicality of such studies, a drawback of this approach is the vastly different timescales of the lifespans of rats and humans $[19,20]$. Given that 1 rat year corresponds to approximately 30 human years, the impact of senescencerelated mechanisms must be considered if Gd levels in rats are assessed after very long time-intervals. In accordance with numerous other studies [54, 56-58] we evaluated Gd retention at a single, specific time point (28 days). Although this does not allow assessment of Gd retention after longer time periods, the results confirm that the elimination curve for gadoteridol from all soft tissue organs is steeper than those of other macrocyclic GBCAs. Moreover, since the measured Gd levels at 28 days after the last administration of ProHance are close to the LOQ, it is highly likely that Gd levels may not be quantifiable by validated analytical methods at later time points.

\section{Conclusions}

In conclusion, our findings confirm and extend those of Bussi et al. [12] in demonstrating considerably lower levels of retained $\mathrm{Gd}$ in brain and soft body tissues of rats at 28 days after the administration of ProHance at a total cumulative dose of $12 \mathrm{mmol} / \mathrm{kg}$ bodyweight than after equivalent cumulative doses of not only Dotarem and Gadovist but also the newly marketed GBCA, Clariscan $^{\mathrm{rm}}$, administered under identical conditions. Furthermore, because of the lower LOQ of the ICP-MS analytical method in this study compared to that of Bussi et al. [12], we were also able to demonstrate significantly lower levels of retained Gd after ProHance in all brain and soft body tissues tested, including the skin and liver. Finally, our findings confirm that GBCA concentration and osmolarity do not influence the amount of retained Gd and show that none of the GBCAs tested have any impact on rat kidney histology, up to the tested cumulative dose.

\section{Abbreviations \\ CPN: Chronic progressive nephropathy; CSF: Cerebrospinal fluid; DOTA: 1,4,7,10-Tetraazacyclododecane-1,4,7,10-tetraacetic acid; \\ ECVP: European College of Veterinary Pathologists; EMA: European Medicines Agency; FDA: Food and Drug Administration; GBCA: Gadolinium-based contrast agent; ICP-MS: Inductively coupled plasma-mass spectrometry; LOQ: Limit of quantitation; WFI: Water for Injection}

\section{Acknowledgements}

We thank Héloïse Vollmer, study director at Charles River Lyon, and her team, for the excellent collaboration. We thank also Zsolt Baranyai and Alessandro Maiocchi (Bracco Imaging) for fruitful discussions regarding chelate stability and physico-chemical properties. 


\section{Authors' contributions}

$\mathrm{SB}$ was a major contributor in writing the manuscript. AC, RC, and AFA analyzed and interpreted the ICP-MS data. AFM contributed to the supervision of statistical analysis. AFE analyzed and interpreted computational studies results. CB peer-reviewed the histological examination of the kidney. MAK, FT, and FM were major contributors in writing the manuscript. All authors read and approved the final manuscript.

\section{Funding}

No public funding

\section{Availability of data and materials}

The datasets used and/or analyzed during the current study are available from the corresponding author on reasonable request.

\section{Ethics approval}

The study design was reviewed and approved by the ethical committee of Charles River France as per the standard document "RatSouris_Tox subchronique_2014avril14 cea".

The study design is in general compliance with the following animal health and welfare guidelines:

- Guide for the care and use of laboratory animals, 2011.

- Decree n² 2013-118 relating to the protection of animals used in scientific experiments described in the Journal Officiel de la République Française on 01 February 2013.

- Directive 2010/63/EU of the European Parliament and of the Council of 22 September 2010 on the protection of animals used for scientific purposes.

\section{Consent for publication}

Not applicable

\section{Competing interests}

All authors were Bracco's employees at the time of study execution.

\section{Author details}

'Bracco Imaging SpA, Bracco Research Centre, Via Ribes 5, 10010 Colleretto Giacosa, TO, Italy. ${ }^{2}$ Bracco SpA, Via Caduti di Marcinelle 13, 20134 Milano, Italy. ${ }^{3}$ Sirius Pathology, 1705 route du Salève, 74350 Cruseilles, France. ${ }^{4}$ Bracco Imaging SpA, Via Caduti di Marcinelle 13, 20134 Milano, Italy.

Received: 5 September 2019 Accepted: 4 December 2019 Published online: 04 February 2020

\section{References}

1. Murata N, Gonzalez-Cuyar LF, Murata K et al (2016) Macrocyclic and other non-group 1 gadolinium contrast agents deposit low levels of gadolinium in brain and bone tissue: preliminary results from 9 patients with normal renal function. Invest Radiol 51:447-453

2. Kanda T, Fukusato T, Matsuda M et al (2015) Gadolinium-based contrast agent accumulates in the brain even in subjects without severe renal dysfunction: evaluation of autopsy brain specimens with inductively coupled plasma mass spectroscopy. Radiology 276:228-232

3. Jost G, Frenzel T, Lohrke J, Lenhard DC, Naganawa S, Pietsch H (2017) Penetration and distribution of gadolinium-based contrast agents into the cerebrospinal fluid in healthy rats: a potential pathway of entry into the brain tissue. Eur Radiol 27:2877-2885

4. Taoka T, Naganawa S (2018) Gadolinium-based contrast media, cerebrospinal fluid and the glymphatic system: possible mechanisms for the deposition of gadolinium in the brain. Magn Reson Med Sci 17:111-119

5. Iliff JJ, Lee H, Yu M et al (2013) Brain-wide pathway for waste clearance captured by contrast-enhanced MRI. J Clin Invest 123:1299-1309

6. Nehra AK, McDonald RJ, Bluhm AM et al (2018) Accumulation of gadolinium in human cerebrospinal fluid after gadobutrol-enhanced MR imaging: a prospective observational cohort study. Radiology 288:416-423

7. Berger F, Kubik-Huch RA, Niemann T et al (2018) Gadolinium distribution in cerebrospinal fluid after administration of a gadolinium-based MR contrast agent in humans. Radiology 288:703-709
8. McDonald RJ, McDonald JS, Kallmes DF et al (2017) Gadolinium deposition in human brain tissues after contrast-enhanced MR imaging in adult patients without intracranial abnormalities. Radiology 285:546-554

9. Robert P, Violas X, Grand S et al (2016) Linear gadolinium-based contrast agents are associated with brain gadolinium retention in healthy rats. Invest Radiol 51:73-82

10. Lohrke J, Frisk AL, Frenzel T et al (2017) Histology and gadolinium distribution in the rodent brain after the administration of cumulative high doses of linear and macrocyclic gadolinium-based contrast agents. Invest Radiol 52:324-333

11. McDonald RJ, McDonald JS, Dai D et al (2017) Comparison of gadolinium concentrations within multiple rat organs after intravenous administration of linear versus macrocyclic gadolinium chelates. Radiology 285:536-545

12. Bussi S, Coppo A, Botteron C et al (2018) Differences in gadolinium retention after repeated injections of macrocyclic MR contrast agents to rats. J Magn Reson Imaging 47:746-752

13. Jost G, Frenzel T, Boyken J, Lohrke J, Nischwitz V, Pietsch H (2019) Longterm excretion of gadolinium-based contrast agents: linear versus macrocyclic agents in an experimental rat model. Radiology 290:340-348

14. ProHance Summary of product Characteristics (SPC). Available via www. medicines.org.uk/emc/product/349/smpc. Accessed 16 Oct 2018

15. Gadovist Summary of product Characteristics (SPC). Available via www. medicines.org.uk/emc/product/2876/smpc. Accessed 26 Mar 2019

16. Dotarem Summary of product Characteristics (SPC). Available via www. accessdata.fda.gov/drugsatfda_docs/label/2017/204781s001 lbl.pdf. Accessed 16 Dec 2019

17. Clariscan Summary of product Characteristics (SPC). Available via www. drugs.com/uk/pdf/leaflet/1012128.pdf. Accessed 16 Dec 2019

18. FDA Guidance for Industry (2005) Estimating the Maximum Safe Starting Dose in initial clinical trials for therapeutics in adult healthy volunteers. U.S. Department of Health and Human Services Food and Drug Administration Center for Drug Evaluation and Research (CDER). Available via https://www. fda.gov/media/72309/download

19. Andreollo NA, Santos EF, Araújo MR, Lopes LR (2012) Rat's age versus human's age: what is the relationship? Arq Bras Cir Dig 25:49-51

20. Sengupta P (2013) The laboratory rat: relating its age with human's. Int J Prev Med 4:624-630

21. EMA Guideline on bioanalytical method validation. (2009) EMEA/CHMP/ EWP/192217/2009 Rev. 1 Corr. 2. Available via https:/www.therqa.com/ forum/good-clinical-practice-discussionforum/thread/3047/

22. FDA Bioanalytical Method Validation - Guidance for Industry (2018) U.S. Department of Health and Human Services Food and Drug Administration Center for Drug Evaluation and Research (CDER). Available via https:/www.fda.gov/files/ drugs/published/Bioanalytical-Method-Validation-Guidance-for-Industry.pdf

23. Chang CA, Francesconi LC, Malley MF et al (1993) Synthesis, characterization, and crystal structures of $\mathrm{M}(\mathrm{DO} 3 \mathrm{~A})(\mathrm{M}=$ iron, gadolinium) and $\mathrm{Na}[\mathrm{M}(\mathrm{DOT} A)]$ ( $\mathrm{M}=\mathrm{Fe}$, yttrium, Gd). Inorg Chem 32:3501-3508

24. Kumar K, Chang CA, Francesconi LC et al (1994) Synthesis, stability, and structure of gadolinium(III) and yttrium(III) macrocyclic poly(amino carboxylates). Inorg Chem 33:3567-3575

25. Platzek J, Blaszkiewicz P, Gries $\mathrm{H}$ et al (1997) Synthesis and structure of a new macrocyclic polyhydroxylated gadolinium chelate used as a contrast agent for magnetic resonance imaging. Inorg Chem 36:6086-6093

26. Frisch MJ, Trucks GW, Schlegel HB et al (2009) Gaussian 09, Revision B.01, Wallingford CT. Gaussian, Inc

27. Dolg M, Stoll H, Savin A, Preuss H (1989) Energy-adjusted pseudopotentials for the rare earth elements. Theor Chim Acta 75:173-194

28. Tomasi J, Mennucci B, Cammi R (2005) Quantum mechanical continuum solvation models. Chem Rev 105:2999-3094

29. Doodford PJ (1985) A computational procedure for determining energetically favorable binding sites on biologically important macromolecules. J Med Chem 28:849-857

30. Maestro, version 10.4, (2015) Schrödinger, LLC, New York. Available via https://www.schrodinger.com/maestro

31. Dean RB, Dixon WJ (1951) Simplified statistics for small numbers of observations. Anal Chem 23:636-638

32. Barbato G, Barini EM, Genta G, Levi R (2001) Features and performance of some outlier detection methods. J Appl Statistics 38:2133-2149

33. Levene H (1960) Robust tests for equality of variances. In: Olkin I, Hotelling $\mathrm{H}$ et al (eds) Contributions to Probability and Statistics: Essays in Honor of Harold Hotelling. Stanford University Press, Palo Alto 
34. Shapiro SS, Bradbury WM (1965) An analysis of variance test for normality (complete samples). Biometrika 52:591-611

35. Snedecor and Cochrane (1967) Statistical methods. The lowa State University Press

36. Welk B, McArthur E, Morrow SA et al (2016) Association between gadolinium contrast exposure and the risk of parkinsonism. JAMA 316 96-98

37. Cocozza S, Pontillo G, Lanzillo R et al (2019) MRI features suggestive of gadolinium retention do not correlate with expanded disability status scale worsening in multiple sclerosis. Neuroradiology 61:155-162

38. Kanda T, Osawa M, Oba H et al (2015) High signal intensity in dentate nucleus on unenhanced T1-weighted MR images: association with linear versus macrocyclic gadolinium chelate administration. Radiology 275:803-809

39. Radbruch A, Weberling LD, Kieslich PJ et al (2015) Gadolinium retention in the dentate nucleus and globus pallidus is dependent on the class of contrast agent. Radiology 275:783-791

40. Radbruch A, Weberling LD, Kieslich PJ et al (2016) Intraindividual analysis of signal intensity changes in the dentate nucleus after consecutive serial applications of linear and macrocyclic gadolinium-based contrast agents. Invest Radiol 51:683-690

41. Aime S (2019) Differences in molecular structure markedly affect GBCA elimination behavior. Radiology 291:267-268

42. Lieleg O, Baumgärtel RM, Bausch AR (2009) Selective filtering of particles by the extracellular matrix: an electrostatic bandpass. Biophys J 97:1569-1577

43. Baranyai Z, Pálinkás Z, Uggeri F, Maiocchi A, Aime S, Brücher E (2012) Dissociation kinetics of open-chain and macrocyclic gadolinium(III)aminopolycarboxylate complexes related to magnetic resonance imaging: catalytic effect of endogenous ligands. Chemistry 18:16426-16435

44. Tóth É, Király R, Platzek J, Radüchel B, Brücher E (1996) Equilibrium and kinetic studies on complexes of 10-[2,3-dihydroxy-(1-hydroxymethyl)propyl]-1,4,7,10-tetraazacyclododecane-1,4, 7-triacetate. Inorg Chim Acta 249:191-199

45. Viguet-Carrin S, Garnero P, Delmas PD (2006) The role of collagen in bone strength. Osteoporos Int 17:319-336

46. Lord ML, Chettle DR, Gräfe JL, Noseworthy MD, McNeill FE (2018) Observed deposition of gadolinium in bone using a new noninvasive in vivo biomedical device: results of a small pilot feasibility study. Radiology 287:96-103

47. Di Gregorio E, lani R, Ferrauto G, Nuzzi R, Aime S, Gianolio E (2018) Gd accumulation in tissues of healthy mice upon repeated administrations of gadodiamide and gadoteridol. J Trace Elem Med Biol 48:239-245

48. Gibby WA, Gibby KA, Gibby WA (2004) Comparison of Gd-DTPA-BMA (Omniscan) versus Gd-HP-DO3A (ProHance) retention in human bone tissue by inductively coupled plasma atomic emission spectroscopy. Invest Radiol 39:138-142

49. White GW, Gibby WA, Tweedle MF (2006) Comparison of Gd(DTPA-BMA) (Omniscan) versus Gd(HPDO3A) (ProHance) relative to gadolinium retention in human bone tissue by inductively coupled plasma mass spectroscopy. Invest Radiol 41:272-278

50. Seely JC, Hard GC (2008) Chronic progressive nephropathy (CPN) in the rat: review of pathology and relationship to renal tumorigenesis. J Toxicol Pathol 21:199-205

51. Gray JE, Weaver RN, Purmalis A (1974) Ultrastructural observations of chronic progressive nephrosis in the Sprague-Dawley rat. Vet Path 11:153-164

52. Hard GC, Khan KN (2004) Invited review: a contemporary overview of chronic progressive nephropathy in the laboratory rat, and its significance for human risk assessment. Toxicol Pathol 32:171-180

53. Birka M, Wentker KS, Lusmöller E et al (2015) Diagnosis of nephrogenic systemic fibrosis by means of elemental bioimaging and speciation analysis. Anal Chem 87:3321-3328

54. Gianolio E, Bardini P, Arena F et al (2017) Gadolinium retention in the rat brain: assessment of the amounts of insoluble gadolinium-containing species and intact gadolinium complexes after repeated administration of gadolinium-based contrast agents. Radiology 285:839-849

55. Robert P, Frenzel T, Factor C et al (2018) Methodological aspects for preclinical evaluation of gadolinium presence in brain tissue: critical appraisal and suggestions for harmonization-a joint initiative. Invest Radiol 53:499-517
56. Jost G, Lenhard DC, Sieber MA, Lohrke J, Frenzel T, Pietsch H (2016) Signal increase on unenhanced T1-weighted images in the rat brain after repeated, extended doses of gadolinium-based contrast agents: comparison of linear and macrocyclic agents. Invest Radiol 51:83-89

57. Robert P, Lehericy S, Grand S et al (2015) T1-weighted hypersignal in the deep cerebellar nuclei after repeated administrations of Gd-based contrast agents in healthy rats: difference between linear and macrocyclic agents. Invest Radiol 50:473-480

58. Rasschaert M, Emerit A, Fretellier N et al (2018) Gadolinium retention, brain T1 hyperintensity, and endogenous metals: a comparative study of macrocyclic versus linear gadolinium chelates in renally sensitized rats. Invest Radiol 53:328-337

\section{Publisher's Note}

Springer Nature remains neutral with regard to jurisdictional claims in published maps and institutional affiliations.

\section{Submit your manuscript to a SpringerOpen ${ }^{\circ}$ journal and benefit from:}

- Convenient online submission

- Rigorous peer review

- Open access: articles freely available online

High visibility within the field

- Retaining the copyright to your article

Submit your next manuscript at $\boldsymbol{\nabla}$ springeropen.com 